\title{
TEMPO SOCIAL, CONFIANÇA E TUTELA AMBIENTAL: A AMBIVALÊNCIA PARA O DIREITO NA (RE)CONFIGURAÇÃO DO ESPAÇO URBANÍSTICO- AMBIENTAL
}

\author{
SOCIAL TIME, CONFIDENCE AND ENVIRONMENTAL PROTECTION: THE \\ AMBIVALENCE FOR THE LAW AT CONFIGURATION ON SPACE URBAN \\ AND ENVIRONMENTAL
}

\author{
${ }^{1}$ Marcio Mamede Bastos de Carvalho
}

\section{RESUMO}

Este trabalho tem por objetivo a análise da inter-relação entre o tempo social a confiança e a tutela do equilíbrio do meio urbanístico-ambiental, bem como a ambivalência entre tais elementos e o Direito. Trataremos inicialmente a dialética entre tempo, Direito e tutela ambiental, tendo como base teórica as lições de Niklas Luhmann e François Ost. Num segundo momento será objeto de análise a proteção fundamental da confiança pelo Direito. Por fim, analisaremos o tempo, o Direito e a confiança na re(configuração) do meio urbanístico-ambiental diante da influência do rápido tempo da contemporaneidade.

Palavras-chave: Tempo social, Proteção à confiança, Tutela ambiental. espaço urbanístico

\begin{abstract}
This study aims to analyze the interrelationship between social time, onfidence and the tutelage of balance of urban and environmental, as well as the ambivalence between these elements and the law. Initially treat the dialectic between time, law and environmental protection, with the theoretical basis of the lessons Niklas Luhmann and François Ost. Secondly will be analyzed in the fundamental protection of confidence by law. Finally, we analyze the time, the law and confidence in re (configuration) of urban and environmental influence on the quick time of contemporaneity.
\end{abstract}

Keywords: Social time, Protection of confidence, Environmental protection, Urban space

\footnotetext{
${ }^{1}$ Mestre em Direito pela Universidade de Caxias do Sul - UCS, Rio Grande do Sul (Brasil). Socio pela Mamede \& Tartari Advogados - M \& T ADVOGADOS, (Brasil). E-mail: marcio.mamede@ hotmail.com
} 


\section{INTRODUÇÃO}

Diante do cenário social contemporâneo de informação quase instantânea, consumismo exacerbado, crescimento econômico que requer cada vez mais recursos naturais, crescimento desordenado das cidades e a necessidade de proteção do equilíbrio urbanísticoambiental, analisaremos no presente trabalho a (re)configuração dos espaços urbanos e a necessária intervenção do Direito para que o crescimento das cidades não avancem ainda mais sobre áreas ambientalmente protegidas.

A perspectiva metodológica aqui adotada tem duas dimensões: uma é a analítica descritiva a partir de categorias de pensamento de autores como Luhmann, Ost, Giddens, e Bauman entre outros; a outra é a crítica.

Quanto ao plano de exposição, inicialmente põem-se em foco, num primeiro momento, a inter-relação entre tempo e Direito e a ambivalência que aquele causa a este na contemporaneidade ao pedir-lhe que permaneça, ao mesmo tempo que pede-lhe que mude, bem como a influência do Direito sobre o tempo social ao traçar os caminhos norteadores para o futuro, formando uma consciência coletiva voltada à proteção do equilíbrio ambiental para as presentes e futuras gerações.

Num segundo momento analisaremos a confiança e seu acolhimento pelo Direito como princípio fundamental, com o fim de sublimar um valor que se mostra inerente à vida em sociedade, já que o homem ao buscar o amparo social busca segurança, e o papel do Direito e do Estado numa concepção mais estável, tem como base a garantia da segurança. Assim, será objeto de análise a relevância deste princípio quando o ato nele fundado se mostrar embasado por ato administrativo permissivo, sobretudo no que se refere ao licenciamento ambiental para instalação de determinado empreendimento.

Por fim, analisaremos, a ambivalência que o tempo traz ao Direito na dinâmica de (re)configuração dos espaços urbanístico-ambientais, diante da expansão de empreendimentos em áreas protegidas, pela influência e rapidez exercidas pelo poder econômico do mercado imobiliário, gerando tensão entre direito individual e a confiança depositada no ato estatal e os direitos transindividuais de proteção do equilíbrio do meio urbano, que merecem respostas em curto tempo pelo Poder Judiciário já que, o tempo aqui se mostra fundamental para a preservação do equilíbrio ambiental. 


\section{O TEMPO SOCIAL, O DIREITO E A TUTELA AMBIENTAL}

Cumpre de logo definir que a noção de tempo aqui discutida tem estreita relação com a sociedade contemporânea em suas características de dinamismo, complexidade e instantaneidade da informação, permeada principalmente pelos avanços tecnológicos dos meios de comunicação em escala mundial e sua influência sobre a cultura social nas mais distantes localidades do planeta terra, criando padrões de comportamentos voltados ao individualismo, imediatismo do consumo/descarte de mercadorias e modos de ser/agir. ${ }^{1}$

A estrutura temporal sob a qual se sustentam as relações sociais contemporâneas, sobretudo as ocidentais, pela influência do modelo de mercado, privilegia o presente. Se sustenta em relações e instituições líquidas ${ }^{2}$ e voláteis, que dão espaço à lógica do agora, da busca dos prazeres e experiências momentâneas, do consumo conspícuo e das artificialidades produzidas pelo mercado.

Giddens (1991) caracteriza o dinamismo da modernidade pelo fato desta promover a separação entre tempo e espaço que é operada por mecanismos de desencaixe ou separação - que, aliados à confiança, podem conduzir à remoção das relações sociais das imediações dos contextos locais e sua reestruturação sobre tempo-espaço indefinidos, tendo como consequência a inserção de indivíduos e coletividades numa sensação de desorientação quanto aos eventos e o conhecimento de nossos destinos.

Pode-se dizer que a contemporaneidade retira o autor social do amparo tradicional de sua pequena comunidade e o submete a influência de organizações muito maiores e impessoais que atuam em escala global, sendo que o acesso dos agentes a informações geradas em contextos globais, e iteração entre acontecimentos regionais e aqueles, pode ser marcada pela justaposição de acontecimentos (locais ou não) no cotidiano social, sendo os meios de comunicação um dos principais alicerces na alteração das condições espaçotemporais e no processo de construção social da realidade, promovendo um significativo

\footnotetext{
${ }^{1}$ A pós-modernidade (Neste sentido LYOTARD, Jean-François. O pós-moderno. Trad. Ricardo Corrêa Barbosa. $3^{a}$ Ed. José Olymoio Editora. Rio de Janeiro: 1988) ou modernidade ("líquida" - BAUMAN, Zygmunt. Modernidade líquida. Rio de Janeiro: Jorge Zahar Ed., 2001; "radicalizada" - GIDDENS, Anthony. As conseqüências da modernidade. Trad. Raul Fiker. São Paulo: UNESP. 1991) têm como conseqüências principais um tempo e espaço diferentes, mediados e/ou influenciados por tecnologias digitais que perpassam as idéias de tempo linear (da modernidade) para um tempo multimídia, pelo qual a "informação" instantânea transforma o imaginário coletivo e sedimenta o vínculo social, modelando e sendo remodelado pela cultura.

${ }^{2}$ Vide BAUMAN, Zygmunt. O mal-estar da pós-modernidade. Rio de Janeiro: Zahar, 1998.
} 
aumento da experiência social mediada pela informação ${ }^{3}$ e não apenas pela percepção das experiências físicas dos acontecimentos.

Conceituar o tempo não se traduz em tarefa singela, como bem confessou Santo Agostinho (2000, p. 278) ao afirmar que sobre ele "Se ninguém me perguntar, eu sei; mas se quiser explicá-lo a quem me fizer a pergunta, já não sei” e acrescentar que "se nada sobrevivesse, não haveria tempo futuro, e se agora nada houvesse, não existia o tempo presente".

Entretanto, a relação entre tempo e Direito é estreita já que um intervêm diretamente no outro - se o Direito (através da Lei) traça os caminhos norteadores de um futuro e a Lei também é sedimentada pelo tempo, a busca de um Governo que possa se mostrar estável e atenda aos anseios sociais está imbricado na conjugação entre a temperança e a justiça. ${ }^{4}$

Conforme Howard Caygill (2000, p. 294), Emmanuel Kant atribui ao tempo a condição de subjetividade, que se traduz no modo humano de receber representações e conhecer dado objeto ou fato por estas representações, como ato fundamental da mente humana (síntese), já que “o conhecimento pode ser reportado a um ato original de síntese” interligando os conceitos aos acontecimentos, objetos e instituições.

Buscando no pensamento de Kant (1996, p.91) uma síntese aporética do tempo, este como condição subjetiva humana, se oferece como elemento de percepção (presente), de reconhecimento (passado) ou de antecipação (futuro) para a conceituação das coisas.

Entretanto, estes três momentos do tempo (passado, presente e futuro), no que se refere à relação com o Direito, devem ser encarados como instituição social (que conjuga uma infinidade de tempos diversos e dinâmicos) e não apenas como um fenômeno físico ou uma ou mais experiências psíquicas.

François Ost (2005, p. 50-86), para analisar o tempo e sua dialética com o Direito, abandona a visão linear daquele (passado-presente-futuro) para reconfigurá-lo de forma dinâmica onde: a memória e o perdão (passado) e a promessa e o questionamento (futuro) não podem ser considerados de forma isolada, uma vez que encontram-se em constante tensão no

\footnotetext{
${ }^{3}$ Conforme Luhmann na grande maioria das vezes são os meios de comunicação que nos apresentam os "fatos" ocorridos em nossa sociedade e no planeta em que vivemos (LUHMANN, Niklas. A realidade dos meios de comunicação. São Paulo: Paulus, 2005).

${ }^{4}$ Acerca do equilíbrio entre "temperança" (sabedoria do tempo) e "justiça" (sabedoria do Direito), analisando a obra Antígona de Sófocles, François Ost adverte que "a cidade boa não supõe apenas a justiça (dike) e a razão (euphronein), mas o equilíbrio dos tempos, a temperança, o justo ritmo dos tempos misturados: a memória do passado, temperada pela capacidade de perdão, a promessa que anima o futuro, acompanhada da capacidade de revisão." (OST, François. Contar a Lei - As fontes do Imaginário Jurídico. Rio Grande do Sul: Unisinos, 2005, p. 76)
} 
Direito, seja para garantir a este estabilidade (tradição e memória como alicerces de formação e manutenção dos laços sociais) ou para conduzir mudanças (promessa e perdão como prospecção e responsabilidade de fincar no presente laços sociais que assegurem um futuro com sentido comum). ${ }^{5}$

Na formação da consciência coletiva voltada à proteção do equilíbrio ambiental, o tempo da promessa se mostra ainda mais importante que o tempo da memória, já que aquele terá como escopo instituir juridicamente uma sociedade com a missão (responsabilidade firmada no presente com vista para o futuro) assumida coletivamente para a proteção do meio ambiente ecologicamente equilibrado.

A problemática desenvolvida na obra de Ost (2005, p. 13-21) tem como fundamento, na formação/manutenção de um bom governo, a (inter)relação entre a sabedoria do tempo ("temperança") e a sabedoria do Direito ("justiça") com base em três teses centrais: I) tempo como instituição social; II) o Direito como instituidor do social (através de leis, sanções e discurso que atribui sentido e valor à vida social) e como interventor temporal e; III) a dialética entre a temporalização social do tempo e a instituição jurídica da sociedade.

Assim como o Direito afeta as formas de criação do tempo (temporalização), este é determinante na força instituinte do Direito, já que, ao passo que o tempo institui o Direito temporaliza (cria o tempo). Ou seja, a norma jurídica é instituída pelo tempo para encontrar uma justa medida entre continuidade e mudança, redizendo o passado e buscando antecipar-se ao futuro, ou pelo menos prometendo um futuro que assegure equilíbrio nas relações sociais.

Se o Direito pode instituir a temporalização ${ }^{6}$, também pode destemporalizar (fuga do tempo comum instituinte) o tempo por variadas formas: a) recusa da mutabilidade do tempo; b) recusa do passado e super valoração do presente; c) pensar no tempo como algo uniforme, homogêneo e contínuo e; d) pensar no tempo social como algo plural e policrônico.

E sob esta ótica de destemporalização que o Direito deve atuar instituindo mecanismos de

\footnotetext{
${ }^{5}$ Para OST o principal papel do Direito é instituir uma sociedade, instituir aquilo que a memória (memória como reconstrução coletiva reflexiva do passado) guarda e a tradição (código de sentidos e de valores que se transmitem através das gerações) visa conservar, bem como, de modo dinâmico, planejar um futuro que preserve ou modifique valores e princípios enraizados numa determinada memória coletiva. (OST, François. O tempo do direito. Bauru: EDUSC, 2005, p. 50-86)

${ }^{6}$ Segundo o prof. Leonel "A temporalização, como desdobramento da simultaneidade de um grande número e de um emaranhamento extremo de interdependência sobre a sequencialidade temporal, é uma estratégia de redução da complexidade, sobretudo da complexidade ligada à não-coincidência do conjunto dos enunciados, das comunicações e das decisões do sistema, com um fundamento único que lhes dá consistência. Somente o tempo, a efetuação factual de um momento a outro da função do sistema, responde à hipercomplexidade produzida, sempre, ao encontro do sistema" (ROCHA, Leonel Severo. Introdução à teoria do sistema autopoiético do direito. Porto Alegre: Livraria do Advogado, 2005, p. 104).
} 
concordância dos tempos, já que sua instituição jurídica figura tanto como ruptura, quanto como ligação das dimensões temporais.

Em que pese o Direito se realizar no presente e planejar o futuro, sua interpretação deve privilegiar uma dialética que conjugue aspectos de sua elaboração pretérita com sua efetivação atual e promessas para o futuro. Caso contrário, pode se despir de sua eticidade e, ao se fundar nos elementos do ser, negligenciar em seu elemento indeclinável - o dever ser.

Luhmann (1983, pp. 72-76) destaca que o Direito, como estrutura de um sistema social, visa, num determinado contexto espaço-temporal, selecionar as expectativas dando a estas sentido, estabilidade (relativa) e coerência para protegê-las dos desapontamentos. Na mesma linha são as lições do prof. Leonel Severo Rocha (2009) ao afirmar que a função do Direito, a partir da seleção de expectativas comportamentais, é produzir "congruência seletiva, disponibilizando caminhos congruentemente generalizados para as expectativas" (Rocha, 2009, p.121), a fim de minimizar transgressões e frustrações.

Conforme Luhmann (1983, p. 48) não existem apenas expectativas, mas também expectativas de expectativas. Ou seja, por existir o outro, minhas expectativas não dependem apenas do meu comportamento, mas também do agir do outro, havendo um duplo horizonte de perspectivas (em si e no outro), de seletividade (decisão acerca da ação ou omissão) e de contingência (a seletividade permite que algo ocorra ou não).

Quanto mais expectativas maior a complexidade e maior a possibilidade de frustração, se fazendo necessário um sistema jurídico que possua critérios de antecipação, para acompanhar uma sociedade voltada para o futuro e diminuir as probabilidades de frustrações.

A noção de antecipação (programação) de expectativas permite então considerar o Direito como um sistema Social. E no contexto social contemporâneo o Direito tem como primeiro e principal problema o tempo, já que toda questão de direito é uma questão de controle do tempo. A operatividade do Direito está imbricada no controle do tempo, havendo nas decisões, conforme salienta o prof. Leonel (2003) uma racionalidade jurídica tradicional de repetição, mas também a necessidade de decisões mais sociopolíticas que considerem o novo tempo da sociedade - a sociedade do futuro.

Só a justa medida entre continuidade e mudança pode conduzir a um Direito que assegure equilíbrio nas relações sociais e proteção de um meio ambiente ecologicamente equilibrado, contra as temporalidades manifestas de sociedades hiperindividualistas e hiperconsumistas que predominam nos países ocidentais. 
Se de um lado, a dinâmica social e do mercado na contemporaneidade conduzem a um individualismo e consumismo frenético de modos de ser e mercadorias em um curto espaço de tempo experimentado e produzido pela subjetividade humana, o meio ambiente possui seu próprio tempo e o homem como parte integrante deste "meio" deve respeitá-lo sob pena de comprometer a existência de ambos.

Imperioso afirmar que a existência e reprodução dos seres vivos de um modo geral, seja no cenário local ou global, tem seu tempo de capacidade de regeneração, baseado em ciclos e processos que se encontram em tensão com o tempo de produção, consumo e descarte de mercadorias das sociedades contemporâneas.

A constante tensão entre o tempo curto da produção industrial, consumo e descarte, com o longo tempo da incubação/restauração natural pode gerar, como tem gerado, danos ao equilíbrio ambiental e escassez/extinção de matéria natural para as presentes e futuras gerações, devendo o Direito intervir na complexa dialética entre homem e natureza de forma a reduzir o domínio unilateral de um sobre o outro.

Ost (1990) defende um projeto dialético entre homem e natureza que não rejeite nem um nem outro e sim que estabeleça uma rede de relações entre estes que denomina como "meio", voltada para o futuro. Ou seja, um trajeto a ser percorrido (movimento) que nos conduza àquilo que somos e não àquilo que nos tornamos. ${ }^{7}$

Entende ainda o autor (Ost, 1990) pela necessária proteção normativa do “meio" e para o "meio". De um regime jurídico que esteja à altura do paradigma ecológico e a complexidade da dialética da relação entre homem, natureza e tempo (presentes e futuras gerações), pautado numa preocupação ética de assumir responsabilidade e moderação na utilização dos recursos naturais a fim de respeitar a igualdade de acesso pelas futuras gerações.

Portanto, para que o Direito se mostre capaz de minimizar a complexidade social e ambiental deve estabelecer uma constante dialética com estas, voltando-se para o futuro

\footnotetext{
${ }^{7}$ Ost defende um projeto para o meio que passa por três etapas. A primeira é epistemológica e adota a idéia de complexidade assentada numa filosofia dialética na busca de um saber interdisciplinar tanto das ciências naturais como das ciências sociais acerca do que ele denomina "novo híbrido" (meio e sujeito à jurisdição). A segunda etapa é ética e se traduz como responsabilidade à coletividade de assumir uma missão para o futuro de legar para às próximas gerações um planeta viável para uma vida sensata. A terceira é jurídica na qual o autor propõe um regime jurídico "para o misto de natureza e cultura, que é o meio", como patrimônio comum que para ele articula de forma complexa "o sujeito e o objeto, o privado e o público, o local e o global, o presente, o passado e o futuro". Nesta última etapa, enquanto o economista fará sob o meio o cálculo de "desenvolvimento sustentável" o jurista dirá se tratar-se de "patrimônio comum" (OST, François. A natureza à margem da lei. Trad. Joana Chaves. Instituto Piaget: 1990, pp. 273-275)
} 
(antecipação), mas também mantendo as conquistas do passado (tradição) a fim de diminuir as probabilidades de frustrações.

Eros Roberto Grau (1996, p. 111), valendo-se das lições de Jhering, adverte que "o direito existe em função da sociedade, e não a sociedade em função dele", e acrescenta que "a realidade social é o presente; o presente é vida - e vida é movimento". Assim, a "interpretação do direito não é mera dedução dele, mas sim processo de contínua adaptação de seus textos normativos à realidade e seus conflitos".

Assim, o Direito como estrutura de um sistema maior (o sistema social) deve selecionar expectativas com base em "valores e princípios simultaneamente enraizados numa memória e portadores de um projeto futuro" (OST, 2005, p. 230) que tenham a proteção do "meio" como compromisso comum. E este projeto/compromisso deve ser engendrado pela vontade (responsabilidade) comum do grupo social - deve ser reflexo da vontade soberana do povo - com base na confiança comum entre estes e os governos, sob pena das manifestações do poder constituído não se traduzirem em um projeto coletivo voltado para o futuro.

Tratamos até aqui da necessária dialética entre tempo social, Direito e proteção ambiental, num contexto contemporâneo e, como vimos acima, um projeto futuro que contemple o "meio" deve ter como base a confiança. É desta que trataremos a seguir.

\section{CONFIANÇA E DIREITO}

Por oportuno, cumpre de logo utilizarmos as lições de Niklas Luhmann (1996, p. 164) acerca da importância da confiança, que para este sociólogo alemão se traduz da seguinte forma: "La confianza no es la única razón del mundo; pero uma concepción muy compleja y estructurada del mundo no podría establecerse sin uma sociedad definitivamente compleja, que a la vez no podría establecerse sin la confianza".

Os estudos de Luhmann (1983) trouxeram notáveis contribuições para o pensamento sócio-jurídico contemporâneo ao apresentarem argumentos teóricos acerca da interdependência da estrutura do Direito e do sistema social, bem como das expectativas que permeiam as relações humanas, possibilitando que o indivíduo possa prever que uma determinada atividade, ou conduta, poderá conduzir a um determinado objetivo.

Conforme Luhmann (1983, p. 48) não existem apenas expectativas, mas também expectativas de expectativas. Ou seja, por existir o outro, minhas expectativas não dependem apenas do meu comportamento, mas também do agir do outro, havendo um duplo horizonte 
de perspectivas (em si e no outro), de seletividade (decisão acerca da ação ou omissão) e de contingência (a seletividade permite que algo ocorra ou não).

Nesta linha, vale lembrar as lições do Prof. Leonel Severo Roche (2009, p. 121) de que a função do Direito, a partir da seleção de expectativas comportamentais, é produzir "congruência seletiva, disponibilizando caminhos congruentemente generalizados para as expectativas", a fim de minimizar transgressões.

Na medida em que o Direito tem por função dar sentido, estabilidade e coerência às expectativas selecionadas a fim de, ao menos, tentar minimizar os desapontamentos, a confiança não repousa sobre a certeza absoluta do Direito e sim na expectativa selecionada por este. ${ }^{8}$

A confiança deve ser compreendida em sua inter-relação com o complexo sistema social, com o "meio" e o Direito, como forma de auxiliar na produção de sentido jurídico e possibilitar, no presente, a redução da complexidade ${ }^{9}$ social.

Para operar, a confiança depende do tempo, já que se encontra entre o passado e o futuro, para permitir que no presente reduza-se a complexidade do sistema social. Para melhor elucidar tal afirmativa, nos valemos das palavras de Darío Mansilla (Luhmann,1996, p. 23) segundo o qual "la confianza es una apuesta, hecha en el presente, hacia el futuro, y que se fundamenta en el pasado (...) no existe, no obstante, certeza"

Ao tratarmos aqui de "certeza" entenda-se como certeza estanque - imutável, absoluta -, uma vez que na história da evolução social aquilo que um dia foi tido como certo pode ser relativizado num futuro próximo (com o passar do tempo).

Assim, confiar não quer dizer eliminar os perigos e incertezas no futuro - o futuro se mostra incerto e permanecerá sendo incerto -, mas agir como se o futuro fosse confiável. Ou seja, em face da incerteza do futuro, o papel do Direito é assegurar expectativas sociais

\footnotetext{
${ }^{8}$ Aqui, se faz necessária a distinção entre os vocábulos "expectativa" e "certeza" em seu sentido absoluto ou imutável. Aquele remete à idéia de condição de quem espera um acontecimento, com base em probabilidades ou na possível efetivação deste, já que se trata de elemento subjetivo e não na certeza de sua concretização. Já a certeza "é uma condição psicológica, ou estado mental, de que as coisas são tais quais o indivíduo as concebe, ou ainda de estar na posse da verdade. Em outras palavras, caracteriza-se pela absoluta adesão a uma idéia, opinião ou fato, desconsiderando qualquer possibilidade de erro ou equívoco." (Fonte: https://pt.wikipedia.org/wiki/Certeza, consulta em 14/07/2015. Em se tratando da ciência não há que se falar em certeza absoluta ou incontestável.

${ }^{9}$ Para Luhmann "Cada experiência concreta apresenta um conteúdo evidente que remete a outras possibilidades que são ao mesmo tempo complexas e contingentes. Com complexidade queremos dizer que sempre existem mais possibilidades do que se pode realizar. Por contingência entendemos o fato de que as possibilidades apontadas para as demais experiências poderiam ser diferentes das esperadas (...) A orientação a partir da regra dispensa a orientação a partir das expectativas. Ela absorve, além disso, o risco de erros da expectativa, ou pelo menos o reduz, isso porque, graças à regra, pode ser suposto que aquele que diverge age erradamente, que a discrepância se origina, portanto, não da expectativa (própria) errada, mas da ação (alheia) errada. Nessa medida a regra alivia a consciência no contexto da complexidade e da contingência"(LUHMANN, Niklas. Sociologia do Direito I. Op. cit. p. 45 e 53).
} 
generalizando-as em suas três dimensões de sentido - temporal, social e prática - mediante a realização de reduções que "possibilitem expectativas comportamentais recíprocas e que são orientadas a partir das expectativas sobre tais expectativas" (Luhmann, 1983, p. 116). ${ }^{10}$

Nesta esteira, a produção de sentido jurídico dá-se graças a relações de confiança e esta pode ser tida como a base do enfrentamento da complexidade e contingência do sistema social contemporâneo pelo sistema jurídico, bem como da tensão homem e meio ambiente.

A teoria dos sistemas sociais autopoiéticos de Luhmann (1996, p. 10) tem como uma de suas premissas a confiança. ${ }^{11}$ E esta é compreendida em três dimensões: a) Subjetiva - é necessário ter confiança e confiar nesta confiança (operação reflexiva); b) Compartilhada - que dá enfoque às expectativas reciprocamente compartilhadas entre indivíduos e; c) Sistêmica - pela qual a confiança se estrutura em expectativas generalizadas em sistemas (como é o sistema jurídico) e organizações, transcendendo aspectos psíquicos ou individuais.

Já o sociólogo britânico Anthony Giddens (1991, p. 52) para tratar da confiança em sua obra As consequências da modernidade se utiliza da definição constante do Oxford English Dictionary segundo o qual o termo seria compreendido como "crença ou crédito em alguma qualidade ou atributo de uma pessoa ou coisa, ou a verdade de uma afirmação". Mas ressalta que na atualidade a "confiança opera em ambientes de risco, nos quais podem ser obtidos níveis variáveis de segurança (proteção contra perigos)" e as relações "de confiança são básicas para o distanciamento tempo-espaço ${ }^{12}$ dilatado em associação com a modernidade".

Tanto Luhmann quanto Giddens, apesar de divergirem no sentido da confiança para os sistemas jurídico e social, apresentam pontos em comum no que se refere à importância da confiança como pressuposto para a existência e manutenção da ordem jurídico-social da atualidade e sua dinâmica.

\footnotetext{
${ }^{10}$ As três dimensões diferem no que se refere à forma de estabilização, pelo sistema jurídico, das expectativas contra desapontamentos. Sendo que na dimensão temporal se dá por meio da normatização, tendo como tática a sanção. Já na dimensão social a estabilização se apóia sobre consenso esperado a partir de terceiro(s), ou suposições fictícias do consenso (as expectativas podem ser institucionalizadas). Por fim, na dimensão prática, as "estruturas de expectativas podem ser fixadas externamente através de um sentido idêntico, compondo uma inter-relação de confirmações e limitações recíprocas". Sobre o assunto, vide LUHMANN, Niklas. Sociologia do Direito I. Op. cit. p. 109-116.

${ }^{11}$ Neste sentido vide: LORES, Luis Gustavo Gomes; BARRETO, Ricardo Menna. Sociologia e Direito: um diálogo a partir das teorias de Niklas Luhmann e Anthony Giddens. Revista da ABRASD - Associação Brasileira de Pesquisadores em Sociologia do Direito, n. ${ }^{\circ}$ 1, outubro de 2011, p. 245-253.

${ }_{12}$ Para Giddens a modernidade é inseparável dos sistemas abstratos, ou na confiança nestes sistemas, que propiciam o desencaixe do tempo-espaço das relações sociais. Os sistemas abstratos são caracterizados pela não necessidade de copresença, onde se é necessário "um rosto", eles se desenvolvem sem a presença de "um rosto" e se caracterizam pela fé em sistemas peritos ou fichas simbólicas, tendo como fundamento a confiança e promovendo o desencaixe tempo-espaço.
} 
A complexa sociedade contemporânea encontra-se em constante evolução, devendo ser observada de forma dinâmica, a partir da idéia de confiança e das contribuições que esta acrescenta na tomada de decisão também e sobretudo no campo do Direito.

Diante de tais argumentos, o ordenamento jurídico deve resguardar a confiança, como pilar da construção de um Direito que minimize os desapontamentos das expectativas legítimas e forneça elementos para um convívio social equânime, calcado no presente, mas sem descuidar das projeções para um futuro socialmente melhor. ${ }^{13}$

Os ordenamentos jurídicos devem tutelar a confiança, como princípio norteador das relações entre particulares e entre estes e o Estado. Ambos devem manter fidelidade à palavra dada e não desapontar as expectativas alheias, ou abusar da confiança depositada, já que estas integram a base indispensável de todas as relações humanas para a manutenção de uma vida coletiva pacífica e um "meio" que se mostre equilibrado.

Cumpre relembrar que estabilidade, segurança e confiança constituem valores fundamentais das sociedades democráticas contemporâneas, dentre elas a brasileira que, a partir da Constituição Federal de 1988, traz em seu Preâmbulo a proteção da confiança como princípio implícito. ${ }^{14}$

Mas apresentar um conceito jurídico deste princípio constitucional (proteção da confiança) não é tarefa das mais fáceis, já que, por vezes o termo é utilizado de forma vaga e os estudos acerca do tema são recentes. ${ }^{15}$

O princípio busca resguardar o status quo (Bestandschutz) evitando que o "crédito" de confiança depositado na conduta estatal seja frustrado por modificações do direito positivo ou por atos emanados dos Poderes Executivo e Judiciário. Em suma, o Poder Público, não poderia, ao menos em tese, adotar nova conduta em contradição com aquelas que

\footnotetext{
${ }^{13}$ Conforme leciona Gerson Branco "[...] a confiança é um pressuposto para a existência de uma ordem jurídicosocial, pois a preservação da confiança, por meio de promessas e do cumprimento de promessas, faz surgir regras que considerem o ponto de vista do outro, permitindo a convivência social. [...] O valor confiança é um dos pilares de todo o direito. Somente existe a possibilidade de convivência social se o valor confiança está presente" (BRANCO, Gerson Luiz Carlos. A Proteção das Expectativas Legítimas Derivadas das Situações de Confiança: elementos formadores do princípio da confiança e seus efeitos. Revista de Direito Privado, $\mathrm{n}^{\circ} 12$, out./dez., São Paulo, 2002, pp. 177 e 181).

${ }^{14}$ Segundo Judith Martins Costa "A confiança dos cidadãos é constituinte do Estado de Direito, que é, fundamentalmente, estado de confiança. Seria mesmo impensável uma ordem jurídica na qual não se confie ou que não viabilize, por meio de seus órgãos estatais, o indispensável estado de confiança. A confiança é, pois, fator essencial à realização da justiça material, mister maior do Estado de Direito." (MARTINS-COSTA, Judith. A re-significação do princípio da segurança jurídica na relação entre o Estado e os cidadãos: a segurança como crédito de confiança. Revista do Centro de Estudos Jurídicos, Brasília, n. 27, out./dez. 2004, p. 16)

${ }^{15}$ Como bem salienta Manuel Frada: "Não existe definição legal de confiança a que possa socorrer-se e escasseiam-se referências normativas explícitas a propósito. O seu conceito apresenta-se fortemente indeterminado pela pluralidade ou vaguidade de empregos comuns que alberga, tornando difícil traçar com ele as fronteiras de uma investigação jurídica" (FRADA, Manuel A. de Castro Portugal Carneiro da. Teoria da confiança e responsabilidade civil. Coimbra: Almedina, 2004, p. 17).
} 
por ele próprio foram emanadas e, assim, frustrar as legítimas expectativas daqueles que acreditaram (confiaram) nos atos estatais anteriores.

Não pretende tal princípio engessar as construções normativas, diante de contextos sociais cada vez mais diversos, mas proteger as legítimas expectativas dos indivíduos, mesmo que ocorridas a partir de atos ilegais ou inconstitucionais, de condutas do Estado que venham a frustrá-las.

Duas funções precípuas podem traduzir no princípio da proteção da confiança legítima, quais sejam: a) atuar como uma proteção das expectativas legítimas e; b) atuar como justificativa da vinculação das partes com a relação jurídica. ${ }^{16}$

No que se refere à aplicação, os elementos para a incidência da confiança podem ser tidos como os seguintes: I) a confiança deve ter como fundamento a conduta de outrem; II) devendo ser justificada; III) deve ter sido feito um determinado "depósito" de confiança; IV) deve haver um comportamento que frustre o "deposito" da confiança criada e das providências nela fundadas. ${ }^{17}$

Vale aqui registrar que, dentre as funções do Estado (Legislativo, Executivo e Judiciário) o princípio da proteção substancial da confiança, de forma mais técnica, se dirige primariamente às atividades do Poder Executivo e Judiciário, pois nos atos emanados destes poderes é possível identificar de forma mais específica, a partir da aplicação do princípio aos casos concretos, situações subjetivas de desapontamentos baseados em legítimas expectativas dos administrados. Nestes casos, apesar de por vezes os atos produzirem efeitos gerais e abstratos, em sua grande maioria são específicos e pessoais.

Os atos emanados do Poder Legislativo, não visam aplicação do Direito a casos específicos, ao menos em tese, e sim inovar a ordem jurídica através de normas com caráter abstrato e geral. Assim, o princípio da proteção da confiança se dirige aos atos emanados do Poder Legislativo de forma secundária, já que a função precípua deste poder - legislar afina-se de forma mais direta aos valores da segurança jurídica em sua feição objetiva (irretroatividade da lei desfavorável, direito adquirido, preocupação com regras transitórias, ato jurídico perfeito, etc). ${ }^{18}$

\footnotetext{
16 Neste sentido, MARTNS, Raphael Manhães. O Princípio da Confiança Legítima e o Enunciado n. 362 da IV Jornada de Direito Civil. Revista CEJ, Brasília, Ano XII, nº 40, p. 11-19, jan./mar. 2008.

${ }^{17}$ Vide ASCENSÃO, José de Oliveira. Cláusulas gerais e segurança jurídica no Código Civil de 2002. Revista Trimestral de Direito Civil, v. 7, nº 28, out./dez. 2006.

18 Luís Roberto Barroso ensina que "A proteção da confiança ou das expectativas legítimas, assim como a boafé, são princípios que se dirigem, primariamente, à Administração Pública e ao Poder Judiciário. Compete a tais órgãos aplicarem o direito aos casos concretos e, nesse ofício, devem atuar com certa constância de previsibilidade, já que lhes cabe preservar a ordem jurídica existente e assegurar a isonomia perante a lei. Nem
} 
Cumpre ressaltar que o princípio em comento (proteção da confiança) teve sua origem na jurisprudência alemã e as linhas traçadas naquele Tribunal influenciaram sua compreensão e desenvolvimento também na jurisprudência brasileira. No qual ele é visto, ao menos primariamente, como método de ponderação, "é antes um princípio de ordem formal ou instrumental, que nos indica como é que devemos resolver colisões que eventualmente surjam entre bens constitucionais de valor equivalente" (Amaral, 2012, p. 26).

Ou seja, tanto a confiança (Preâmbulo) quanto a proteção do equilíbrio ambiental (art. 225) se traduzem em “... valores e princípios simultaneamente enraizados numa memória e portadores de um projeto futuro" (OST, 2005, p. 230), sendo a Constituição Brasileira de 1988 a materialização das promessas que o corpo social fez a si próprio e instrumento jurídico de ligação entre os tempos (passado, presente e futuro), sendo os Tribunais responsáveis por, após a ponderação destes valores, decidirem contra o tempo homogêneo e linear da contemporaneidade ou respeitando o tempo ambiental, sobretudo na dialética entre mudança e permanência do "meio" urbano.

Trataremos a seguir da (re)configuração deste "meio" (urbano) e a ambivalência do Direito em relação ao tempo curto da evolução e o tempo próprio da preservação ambiental.

\section{4 (RE)CONFIGURAÇÃO DO ESPEÇO URBANÍSTICO-AMBIENTAL: UMA AMBIVALÊNCIA PARA O DIREITO}

O tempo é ao Direito uma dimensão essencial, mas sobretudo ambivalente, ao pedirlhe que permaneça ao mesmo tempo que pede-lhe que mude. O Direito tendente à continuidade só ordenará se for dotado de alguma estabilidade ao passo que, só ordenará eficazmente se souber responder às mudanças de um sistema social cada vez mais dinâmico.

Um projeto jurídico, portanto voltado para o futuro, deve dialogar com o sujeito (homem) como ser social, com o "objeto" (meio ambiente natural e artificial) e com as nuances do tempo na contemporaneidade, de modo a proteger os interesses coletivos (bem- estar social e equilíbrio ambiental) em detrimento dos interesses hiperindividuais impostos pelo mercado econômico voltado para o agora.

mesmo o legislador poderá ser totalmente indiferente a tais princípios constitucionais. [...]” (BARROSO, Luís Roberto. Mudança da Jurisprudência do Supremo Tribunal Federal em matéria tributária. Segurança jurídica e modulação dos efeitos temporais das decisões judiciais. Revista de Direito do Estado, Rio de Janeiro, n.2, abr/jun 2006, p. 277-278. 
Não se quer dizer que o Direito deva relegar a proteção individual, em especial a confiança, liberdade e propriedade privada, mas tais direitos fundamentais, constitucionalmente previstos e defendidos, devem ser interpretados de forma que o todo (homem e meio) sejam preservados.

O Estado (através de suas esferas legislativa, executiva e judiciária) não pode retroceder na proteção até aqui alcançada da coletividade e do equilíbrio ambiental, ao passo que deve ampliar tal proteção como compromisso presente para garantir equidade às futuras gerações.

Nos deparamos, principalmente nos grandes centros urbanos, com a rápida (re)configuração dos espaços a partir de processos de urbanização sem controle, sem fiscalização, sem qualquer respeito às diretrizes urbanísticas e ambientais e, ainda, em alguns casos, com o aval estatal para construção em biomas protegidos.

Conforme leciona Rech (2010, p. 36), como ramo do direito público, cujas normas tem natureza compulsória e cogente, o direito urbanístico tem como objetivo a sistematização e organização dos espaços urbanos (habitáveis ou não) "garantindo a estes sustentabilidade ambienta, econômica e social", com vistas a uma sadia qualidade de vida.

Ocorre que o planejamento urbanístico-ambiental de determinado local, pode sofrer, como sofre, mutações ao longo do tempo, que podem causar frustrações de expectativas, legítimas ou não, individuais ou coletivas. E a tensão entre mudança e permanência pode ser remediada pelo Direito em cada caso concreto.

Para melhor elucidar tal assertiva, vale referir que atualmente tramita na Câmara do Deputados o Projeto de Lei n. ${ }^{\circ}$ 6830/2013, que tem como objeto alterar a Lei n. ${ }^{\circ}$ 12.651/2012 (Novo Código Florestal) a fim de que o Legislativo Municipal posse dispor sobre as áreas de proteção permanente nos aglomerados urbanos e regiões metropolitanas.

No cenário legislativo brasileiro há alguns mecanismos que visam garantir a participação direta ${ }^{19}$ e indireta ${ }^{20}$ da população na proteção da qualidade ambiental, sendo que as audiências públicas se traduzem em momento do procedimento de licenciamento ambiental voltado a informar e acolher sugestões dos participantes, não possuindo poder de condicionar a decisão administrativa às sugestões dos participantes na audiência.

\footnotetext{
19 Podemos aqui citar, a título exemplificativo, como formar de participação direta: iniciativa popular nos procedimentos legislativos (art. 61, caput e $\S 2^{\circ}$ da CF/1988); plebiscito e referendos (art. 14, incisos I e II da CF/1988); atuação de representantes da sociedade civil em órgãos colegiados dotados de poderes normativos; participação em audiências públicas (art. 11, § $2^{\circ}$, da Resolução 001/86 do CONAMA).

${ }^{20}$ Como exemplo temos a Ação Civil Pública Ambiental, com previsão na Lei n. ${ }^{\circ}$ 7.347/85.
} 
A legislação atual acerca do licenciamento ambiental considera que a decisão da administração pública, através do órgão licenciador, não está vinculada ao que restou delineado como críticas e sugestões na audiência pública, tendo esta caráter consultivo ${ }^{21}$, o que delimita de forma considerável a participação popular efetiva em tais procedimentos, sob o argumento de que a decisão é atribuição do poder discricionário do órgão ambiental. Entretanto, na audiência pública do licenciamento ambiental, não se pode simplesmente desconsiderar as deliberações sociais sem que haja motivação sobre o seu não acolhimento.

No que se refere ao ato administrativo, sobretudo no ato de licenciar projeto de construção que gere (re)configuração do espaço urbano, pode-se perceber que a ambivalência para o Direito causada pelo tempo se mostra ainda mais evidente, ainda mais quando os interesses em tensão se baseiam na confiança do cidadão no ato (direito individual) e a proteção do "meio" (direito transindividual).

Nesta esteira são colocadas em tensão as relações entre individual e coletivo, homem e meio ambiente, poder econômico e equilíbrio ambiental, passado (continuidade) e futuro (mudança). Tensão esta que, na maioria das vezes, é decidida em âmbito judicial, cabendo ao juiz estabelecer uma dialética entre este misto de natureza e cultura, numa justa medida da continuidade e da mudança que assegura o equilíbrio das relações sociais e da proteção do "meio" do qual fazemos parte.

O principal pacto para o futuro da proteção do equilíbrio ambiental - a Constituição Federal de $1988^{22}$ nos fornece um aparato de proteção pelo Estado e pela coletividade do equilíbrio do "meio", mas o que vemos na prática é a apropriação de áreas

\footnotetext{
${ }^{21}$ Neste sentido, sustenta Machado: "A audiência pública - devidamente retratada na ata e seus anexos - não poderá ser posta de lado pelo órgão licenciador, como o mesmo deverá pesar os argumentos nela expendidos, como a documentação juntada. Constituirá nulidade do ato administrativo autorizado - que poderá ser invalidada pela instância administrativa superior ou via judicial - quando o mesmo deixar de conter os motivos administrativos favoráveis ou desfavoráveis ao conteúdo da ata e de seus anexos." (MACHADO, Paulo Afonso Leme. Direito Ambiental Brasileiro. São Paulo: Malheiros, 2002, p. 102)

${ }^{22}$ Art. 23, I, III, VI, VII e XI - Define como competência comum da União, Estados e Distrito Federal e dos Municípios, a conservação do Patrimônio Público, dos bens paisagísticos, do meio ambiente, e a fiscalização da pesquisa e exploração dos recursos hídricos e minerais;

Art. 24, VI a VIII - Coloca como competência concorrente da União, Estados e Distrito Federal o ato de legislar sobre o meio ambiente, patrimônio paisagístico e responsabilidade por danos ambientais; Art. 30, I, VIII e IX Confere ao município a competência para legislar sobre temas de importância e interesse local, promover o ordenamento territorial e proteção do patrimônio histórico-cultural local; Art. 170, VI - Estabelece como princípio da ordem econômica a defesa do meio ambiente; Art. 186, II - Acrescenta a preservação do meio ambiente entre os requisitos para o atendimento da função social da propriedade; Art. 216, V e $\S 1^{\circ}$ - Atribui ao Poder Público o dever de proteção do patrimônio cultural brasileiro, nele incluídas as áreas de valor paisagístico, arqueológico e ecológico; Art. 225 - Todos tem direito ao meio ambiente ecologicamente equilibrado, bem de uso comum do povo e essencial à sadia qualidade de vida, impondo-se ao Poder Público e à coletividade o dever de defendê-lo e preservá-lo para as presentes e futuras gerações.
} 
urbanas comuns pelo mercado imobiliário, o que demonstra a atuação rápida do mercado e o vagar lento do tempo da ação estatal.

$\mathrm{Na}$ região metropolitana de Porto Alegre/RS pode-se perceber claramente a prática do que foi acima afirmado.

O território denominado Ilha Grande dos Marinheiros constitui a união ambivalente entre passado (ocupação por pescadores, população de baixa renda) e futuro imediato (ocupação por população de média e alta renda) em áreas majoritariamente de preservação permanente.

Enquanto o mercado imobiliário (re)configura o território daquela ilha e obtém muito lucro ${ }^{23}$ com a venda de áreas que deveriam ser comuns, o lento vagar do Estado tenta proteger aquele patrimônio ambiental, sem sucesso, já que durante a metropolização da cidade o Plano Básico para o Parque Estadual do Delta do Jacuí (1979), a criação da Unidade de Conservação de Uso Sustentável - APAEDJ (2005) - e o PAE (2010) não frearam a ocupação irregular daquela região, que aumentou em 50\% dos anos de 1970 a 2000.

De acordo com as diretrizes do Sistema Estadual de Unidades de Conservação (SEUC), a APAEDJ tinha um tempo hábil de três anos para implantar o Plano de Manejo após a sua criação. Porém, a SEMA não conseguiu implantá-lo, e na tentativa de frear a ocupação urbana, criou o Plano de Ações Emergenciais através da Portaria nº. 007, de 03 de fevereiro de 2010. Após a implantação do Plano de Ações Emergenciais (PAE-APAEDJ), as ocupações de médio e grande impacto ambiental, impulsionados pela ação do mercado imobiliário, continuam acontecendo, enquanto se aguarda a formulação e aprovação do Plano de Manejo.

Situações similares são vividas não apenas em Porto Alegre, mas em diversos municípios do nosso país, competindo ao Direito, que se pretende eficaz na preservação do equilíbrio ambiental, responder em tempo hábil as (re)configurações urbanístico-ambientais realizadas de forma legal ou não pelo poder econômico do mercado imobiliário.

Entretanto, há modificações do espaço urbanístico-ambiental que operam sob o manto da legalidade, ao menos aparente, de empreendimentos imobiliários que receberam o aval estatal (licenciamento ambiental) para sua implementação em áreas ambientalmente ou urbanisticamente protegidas. O que gera tensão entre o direito individual e a confiança

\footnotetext{
${ }^{23}$ Em consulta de terrenos à venda naquele local podemos nos deparar com descrições como esta: "Excelente terreno na Ilha Grande dos Marinheiros, à beira do rio Guaíba, medindo 31x80m, com befeitorias: Aterrado com autorização da FEPAN, Gramado, Quiosque com bar, Piscina,Praia com areias brancas e Trapiche para barco. Venha desfrutar do mais belo por do Sol!”. E valores, em média, de R\$1,5 milhão. Fonte: http://www.luagge.com.br/venda terreno-ilha-dos-marinheiros-porto-alegre 100241376, consulta em $14 / 08 / 2015$.
} 
depositada no ato estatal e os direitos transindividuais de proteção do equilíbrio do meio urbano, que merecem respostas em curto tempo pelo Poder Judiciário já que, o tempo aqui se mostra fundamental para a preservação do meio ambiente uma vez que iniciadas as obras o dano pode se mostrar irreversível.

Passemos então à análise de algumas situações de tensão entre os direitos fundamentais da confiança no ato estatal e preservação do equilíbrio do meio ambiente, na jurisprudência dos Tribunais pátrios.

O primeiro trata de licença concedida pelo órgão ambiental do município de Vitória/ES para parcelamento de solo urbano para a construção de loteamento residencial. Ocorre que, para a construção do loteamento, se fazia necessário o aterramento de terreno de mangue que, sabe-se, ou ao menos se deveria saber, tratar-se de área de preservação ecológica permanente. Nesta situação em especial o Ministério Público ingressou com ação civil pública contra o proprietário do empreendimento e contra a municipalidade, por sua vez o proprietário do empreendimento suscitou em sua defesa estar amparado no direito constitucional de propriedade e no direito adquirido (ao nosso entender a concepção correta seria a do caráter subjetivo da segurança jurídica - proteção à confiança), através da licença para construção da infra-estrutura, de continuar com as obras. Entretanto, a decisão ponderou que a municipalidade poderia "no âmbito de sua competência legislativa suplementar, alargar a proteção ambiental, sendo-lhe vedado restringi-la", bem como a inexistência de direito adquirido de poluir. As obras foram interrompidas. ${ }^{24}$

\footnotetext{
${ }^{24}$ Ementa da decisão: DIREITO AMBIENTAL. LOTEAMENTO E URBANIZAÇÃO PREVISTO EM PLANO DIRETOR DO MUNICÍPIO DE VITÓRIA. LICENÇA PARA CONSTRUÇÃO. ATERRAMENTO DE ÁREA ENQUADRADA COMO ÁREA DE MANGUE. SUPREMACIA DA CONSTITUIÇÃO E DO CÓDIGO FLORESTAL. INEXISTÊNCIA DE DIREITO ADQUIRIDO DE POLUIR. Preliminares superadas. A responsabilidade por dano ambiental é objetiva e a legitimação passiva para a causa decorre do conceito de poluidor do art. 3o, IV, da Lei no 6.938/81. Aplica-se ao caso concreto a regra do art. 400, II, do CPC, quanto à dispensa na produção de prova testemunhal. Tendo sido o laudo pericial juntado aos autos sete anos antes da conclusão para sentença, afasta-se a argüição de cerceamento de defesa. A via eleita (ação civil pública) é a adequada, conforme art. 1o, I, da Lei no 7.347/85. Não há identidade entre a presente ação civil pública e o mandado de segurança impetrado junto à Justiça do Estado por VIVACQUA IRMÃOS S/A contra ato do Secretário de Estado de Meio Ambiente do Espírito Santo. Conseqüentemente, não há que se falar em ofensa à coisa julgada. Ambos os Juízos atuaram nos limites de sua competência. Eventual necessidade de reunião de ações, perante a Justiça Federal, não questionada. No mérito, o exercício do direito de propriedade sofre limitação constitucional. Incidência, no caso concreto, das normas previstas nos artigos 23, VI e VII, 24, VI, 30, II e 225 da CRFB/88. O parcelamento ou loteamento do solo urbano, pelo Município, deve observar a proteção, definida em lei, às áreas de preservação ecológica. O Município, ao editar Plano Diretor e definir quais as áreas de zoneamento urbano, pode, no âmbito de sua competência legislativa suplementar, alargar a proteção ambiental, sendolhe vedado restringi-la. A área em questão foi considerada, conforme prova pericial, terreno de mangue, e é objeto de proteção conforme art. 2o da Lei Federal no 4.771/65 (Código Florestal). A concessão à $1^{a}$ apelante de licença de construção da infra-estrutura do loteamento Bairro Jabour, pelo Município, permitindo-lhe o aterramento de área de preservação permanente, não cria direito adquirido de poluir. Inexistência de licença ambiental ou de estudo de impacto ambiental. Apelações improvidas. (AC 289198 ES 2002.02.01.023408-5,
} 
Neste caso verifica-se, portanto, a prevalência da proteção ambiental mesmo diante da concessão de licença para construção e da confiança nela depositada pelo particular no ato da autoridade pública.

Num segundo caso, o Ministério Público do Estado de Santa Catarina se insurgiu contra licença ambiental, concedida pela autoridade municipal, de construção em local em que existia uma fonte de origem portuguesa (patrimônio histórico), requerendo assim liminar para suspender os efeitos da licença. No entanto, mesmo a decisão tendo reconhecido a existência da fonte e seu valor histórico-cultural, bem como o parecer desfavorável do MP à construção, entendeu que este não tem caráter vinculante e que o pedido deveria ser julgado de forma desfavorável por perda do objeto, já que a fonte portuguesa já havia sido demolida. A lentidão na aplicação do Direito acarretou, portanto, a supressão do bem ambiental protegido. $^{25}$

Nestes dois casos apreciados por Tribunais Estaduais, pode-se perceber três elementos fundamentais: a) houve ato administrativo, através da concessão de licença ambiental, permitindo ao titular do empreendimento que realizasse as obras; b) o ato de concessão da(s) licença(s) gerou no empreendedor a confiança legítima de que estava agindo dentro dos mandamentos de direito e que seus interesses seriam preservados e; c) em determinada medida, uns mais e outros menos, há danos ambientais em decorrência da execução e manutenção dos empreendimentos, sendo que no primeiro as obras foram interrompidas e no segundo mantidas.

Nesta senda também já decidiu o Egrégio Superior Tribunal de Justiça, em determinar a demolição de empreendimento que possuía licença para construção que não

Relator(a) Desembargador Federal THEOPHILO MIGUEL, Sétima Turma Especializada, DJU, data 01/08/2007, página 139)

${ }^{25}$ Ementa da decisão: AMBIENTAL. LICENÇA SUSPENSA COM BASE EM RECOMENDAÇÃO DO MINISTÉRIO PÚBLICO, QUE NÃO TEM FORÇA VINCULANTE. AUSÊNCIA DE PROCESSO ADMINISTRATIVO. ILEGALIDADE. SUSPENSÃO QUE VISAVA A REALIZAÇÃO DE ESTUDO PARA FINS DE PRESERVAÇÃO HISTÓRICA. FONTE DE ORIGEM PORTUGUESA, JÁ DEMOLIDA, COM RESPALDO EM ALVARÁ VÁLIDO. OBJETO ESVAZIADO. RECURSO PROVIDO PARA CONCEDER A LIMINAR. "1. O Tribunal Pleno, no RE 594.296, rel. Min. Dias Toffoli, DJe de 13/02/2012, processo submetido à sistemática da repercussão geral, decidiu que a revogação de atos administrativos de que já decorreram efeitos concretos deve ser precedida por procedimento administrativo em que se oportunize a manifestação do interessado, sob pena de infringência às garantias do contraditório e da ampla defesa." (AgR no RE n. 499.791, rel. Min. Teori Zavascki, Segunda Turma, j. 20-8-2013) "A recomendação do Ministério Público desfavorável ao licenciamento ambiental de certa localidade, dado o seu caráter meramente enunciativo e a ausência de previsão legal, não contém força cogente capaz de trancar ou suspender o processo administrativo para obtenção de licença ambiental instaurado no órgão ambiental estadual (art. 37, 'caput', da Constituição Federal), independentemente da decisão (positiva ou negativa) que vier a ser tomada. (TJSC, Reexame Necessário em Mandado de Segurança n. 2010.044563-8, da Capital, j. 30.11.2010)" (RN n.

2009.057465-0, da Capital, rel. Des. Pedro Manoel Abreu, Terceira Câmara de Direito Público, j. 12-4-2011). (TJSC, Agravo de Instrumento n. 2013.078339-3, de Joinville, rel. Des. Paulo Henrique Moritz Martins da Silva, j. 18-11-2014). 
obedeciam as legislações urbanístico-ambientais, bem como ao determinar obediência a restrições convencionadas na esfera particular. ${ }^{26}$

Cumpre ressaltar que, somente associada a dimensão cultural é que a dimensão temporal pode se tornar elemento ativo da efetivação dos direitos fundamentais, em especial o direito das presentes e futuras gerações a viverem num ambiente sadio.

O rápido tempo das re(configurações) dos cenários urbanos devem encontrar no Direito, como projeção (movimento) e sobretudo na aplicação da norma, diante da ineficácia da Administração Pública em diversos casos concretos, sua necessária temporalização a fim de que o tempo próprio do meio possa ser respeitado.

Peço vênia para colacionar parte do voto do E. Ministro Herman Benjamin (REsp 302.906/SP) em defesa da garantia fundamental da qualidade urbanístico-ambiental, diante da ambivalência trazida ao Direito pelo tempo. Sobretudo do tempo da contemporaneidade. Verbis:

\begin{abstract}
O Judiciário não desenha, constrói ou administra cidades, o que não quer dizer que nada possa fazer em seu favor. Nenhum juiz, por maior que seja seu interesse, conhecimento ou habilidade nas artes do planejamento urbano, da arquitetura e do paisagismo, reservará para si algo além do que o simples papel de engenheiro do discurso jurídico. E, sabemos, cidades não se erguem, nem evoluem, à custa de palavras. Mas palavras ditas por juízes podem, sim, estimular a destruição ou legitimar a conservação, referendar a especulação ou garantir a qualidade urbanístico-ambiental, consolidar erros do passado, repeti-los no presente, ou viabilizar um futuro sustentável.
\end{abstract}

O Direito, com o "progresso" social, tecnológico e político, como a grande maioria das áreas do saber, se viu obrigado a enfrentar problemas relativos à sua eficiência (teoria) e eficácia (prática) diante do tempo dinâmico da pós-modernidade e sua multiplicidade de interesses, devendo ser conduzido com "temperança" (sabedoria do tempo), a justa medida da continuidade e da mudança que assegura o equilíbrio das relações sociais e do equilíbrio do "meio" urbanístico-ambiental.

\title{
5 CONCLUSÃO
}

Por excelência, a Constituição Federal é o elo de ligação com o futuro e guardiã das promessas que o corpo social pôde fazer a si próprio no passado e pode fazer no presente,

\footnotetext{
${ }^{26}$ Vide REsp 1394025/MS, Rel. Ministra ELIANA CALMON, SEGUNDA TURMA, julgado em 08/10/2013, DJe 18/10/2013 e REsp 302.906/SP, Rel. Ministro HERMAN BENJAMIN, SEGUNDA TURMA, julgado em 26/08/2010, DJe 01/12/2010.
} 
a fim de diminuir a frustração de suas legítimas expectativas de um meio ambiente sadio, para as presentes e futuras gerações.

Se o Direito, como estrutura de um sistema social, tem como base, num determinado contexto espaço-temporal, selecionar as expectativas dando a estas sentido, estabilidade e coerência, a fim de protegê-las dos desapontamentos que se mostram cada vez mais latentes no modo de organização das sociedades hiperindividualistas e hiperconsumistas da contemporaneidade, deve encontrar uma justa medida entre permanência e mutabilidade, já que existe em função da sociedade.

A (re)configuração dos espaços urbanístico-ambientais traz para o Direito uma demanda ambivalente, em especial na efetivação das normas fundamentais de proteção ambiental, entre se omitir e agir, sucumbir ao poder econômico e preservar os interesses transindividuais, permanecer e mudar, já que a efetivação do direito material conduz à necessária efetividade da tutela jurisdicional, como direito fundamental no sentido funcional ( $\operatorname{art} .5^{\circ}$, inciso XXV da Constituição Federal de 1988).

Aos juristas foi confiada a missão de guardar a memória social, não para a manutenção do passado, mas para garantir no presente e no futuro o cumprimento das promessas realizadas naquela fração temporal. Caminhar para o futuro não quer dizer livrar-se do passado, mas de submetê-lo "ao processo permanente, crítico e reflexivo de revisão, que ao mesmo tempo lhe garanta uma consciência mais exata de sua singularidade e lhe organize uma abertura dialógica com as outras tradições num espaço público de discussão" (OST,

2005, p. 147), a fim de que a dialética entre tempo e direito conduza à preservação do homem e do equilíbrio do meio em que vive.

\section{REFERÊNCIAS}

AGOSTINHO, Aurélio [Santo Bispo de Hipona]. Confissões. Petrópolis: Vozes, 2000.

AMARAL, Maria Lúcia. O tempo e a proteção da confiança. V Encontro dos Professores Portugueses de Direito Público, janeiro de 2012 / Faculdade de Direito da Universidade de Lisboa; org. Carla Amado Gomes. - Lisboa: Alameda, 2012.

ASCENSÃO, José de Oliveira. Cláusulas gerais e segurança jurídica no Código Civil de 2002. Revista Trimestral de Direito Civil, v. 7, nº 28, out./dez. 2006.

BARROSO, Luís Roberto. Mudança da Jurisprudência do Supremo Tribunal Federal em matéria tributária. Segurança jurídica e modulação dos efeitos temporais das decisões judiciais. Revista de Direito do Estado, Rio de Janeiro, n.2, abr/jun 2006.

BRANCO, Gerson Luiz Carlos. A Proteção das Expectativas Legítimas Derivadas das Situações de Confiança: elementos formadores do princípio da confiança e seus efeitos. Revista de Direito Privado, $\mathrm{n}^{\mathrm{o}}$ 12, out./dez., São Paulo, 2002.

CAYGILL, Howard. Dicionário Kant. Rio de Janeiro: Jorge Zahar, 2000. 
FRADA, Manuel A. de Castro Portugal Carneiro da. Teoria da confiança e responsabilidade civil. Coimbra: Almedina, 2004.

BAUMAN, Zygmunt. O mal-estar da pós-modernidade. Rio de Janeiro: Zahar, 1998. Modernidade líquida. Rio de Janeiro: Jorge Zahar Ed., 2001.

GRAU, Eros Roberto. O direito posto e o direito pressuposto. São Paulo: Malheiros, 1996.

GIDDENS, Anthony. As conseqüencias da modernidade. Trad. Raul Fiker. São Paulo: UNESP. 1991.

KANT, Immanuel. Crítica da razão pura. São Paulo: Nova Cultural, 1996.

LYOTARD, Jean-François. O pós-moderno. Trad. Ricardo Corrêa Barbosa. $3^{\mathrm{a}}$ Ed. José Olymoio Editora. Rio de Janeiro: 1988.

LORES, Luis Gustavo Gomes; BARRETO, Ricardo Menna. Sociologia e Direito: um diálogo a partir das teorias de Niklas Luhmann e Anthony Giddens. Revista da ABRASD - Associação Brasileira de Pesquisadores em Sociologia do Direito, n. ${ }^{\circ}$ 1, outubro de 2011.

LUHMANN, Niklas. Sociologia do Direito I. Rio de Janeiro: Edições Tempo Brasileiro, 1983. Confianza. Universidad Iberoamericana. México: Anthropos Editorial, 1996. A realidade dos meios de comunicação. São Paulo: Paulus, 2005.

MACHADO, Paulo Afonso Leme. Direito Ambiental Brasileiro. São Paulo: Malheiros, 2002.

MARTINS-COSTA, Judith. A re-significação do princípio da segurança jurídica na relação entre o Estado e os cidadãos: a segurança como crédito de confiança. Revista do Centro de Estudos Jurídicos, Brasília, n. 27, out./dez. 2004

MARTINS, Raphael Manhães. O Princípio da Confiança Legítima e o Enunciado n. 362 da IV Jornada de Direito Civil. Revista CEJ, Brasília, Ano XII, nº 40, p. 11-19, jan./mar. 2008.

OST, François. A natureza à margem da lei. Trad. Joana Chaves. Instituto Piaget: 1990. O tempo do direito. Bauru: EDUSC, 2005. Contar a Lei - As fontes do Imaginário Jurídico. Rio Grande do Sul: Unisinos, 2005.

RECH, Adir Ubaldo; RECH, Adivandro. Direito urbanístico: fundamentos para a construção de um plano diretor sustentável na área urbana e rural. Caxias do Sul, RS: EDUCS, 2010.

ROCHA, Leonel Severo. Introdução à teoria do sistema autopoiético do direito. Porto Alegre: Livraria do Advogado, 2005.

ROCHA, Leonel Severo; ATZ, Ana Paula; MENNA BARRETO, Ricardo de Macedo. Direito e Ciberespaço: uma Observação Sistêmica da Publicidade no Comércio Eletrônico. Revista de Ciênciais Sociais (UGF) Rio de Janeiro (RJ), v. 14, p. 113- 132, 2009. 